\title{
De Tolstoi a Kierkegaard: ¿El inevitable y humano descuido del instante?
}

\author{
Hernán R. Mora Calvo*
}

Recibido: Mayo 2012 • Aceptado: Julio 2012

RESUMEN

Tolstoi y Kierkegaard son considerados filósofos existencialistas cristianos. Para ambos la vida es un reto: la conciencia revela el desperdicio de la vida. Sin embargo, el tiempo es también para la salvación.

Palabras clave: conciencia, culpa, existencia, razón de ser y de vivir, tragedia, vida.

\section{ABSTRACT}

Tolstoi and Kierkegaard are considered to be christian existencialist philosophers. Life is a challenge for both of them: the conscience reveals the waste of life. Howere, time is also for salvation.

Key words: Conscience, fault (guilt), existence, raison of being, raison of life, tragedy, life.

";Oh mente humana, que el hado ignoras $y$ la suerte por venir, y engreída por los sucesos favorables, no guardas límites ni modo!"

(Virgilio, La Eneida X, 500)

"Es lo mismo. Sea una cosa u otra, no he de estar peor" (Tolstoi, 1991: 12); “¿Procedo bien o mal? No lo sé, pero no me importa. Me da igual" (p. 141). Así se expresan, respectivamente, Maslova (la acusada de robo y asesinato) y Nejliudov (el príncipe y el culpable) en dos

* Licenciado en Filosofía por la Universidad de Costa Rica. Sus investigaciones se centran en el área de Patrología griega. Es profesor de Filosofía en la Universidad de Costa Rica y en la Universidad Estatal a Distancia. E-mail: hemojv@yahoo.es 
pasajes de Resurrección, de León Tolstoi (1991). Estas expresiones caracterizan a los personajes medulares de la obra y conllevan una especie de resumen de vida de cuanto han sido, son y pretenden seguir siendo. Es nuestro deseo intentar ofrecer al lector cómo en el autor ruso hay ciertos lineamientos que pueden describirse como esencialmente trágicos. De igual manera, es nuestro intento tratar de hallar en este discurrir tolstoiano sobre el ser humano un parangón con el pensamiento de Sören Kierkegaard, aquel danés que algunos consideran el padre del existencialismo.

En primer lugar, trataremos de situarnos en esa obra tolstoiana, a fin de hallar la experiencia trágica y a partir de estas observaciones discurriremos hacia Kierkegaard y sus meditaciones en torno a la existencia, la responsabilidad, la libertad y el ejercicio del cristianismo y del momento. En ese segundo propósito, Tolstoi no es ausente, sino el conversador alterno.

\section{Todo da igual}

"Nada puede estar peor", esa es la expresión -habíamos dichode Maslova. Ella es una joven de 27 años, una sirvienta, una sirvienta sui generis, pues queda huérfana desde muy niña, crece en medio de familias adineradas que, viendo sus dotes personales, deciden darle una educación esmerada; con excepción de sus refinadas costumbres, su celo en el trabajo y su agudo pensamiento, no posee nada más. Maslova es, entonces, una empleada doméstica con preparación y modales aristocráticos.

Nejliudov es un aristócrata por nacimiento, es príncipe y conoce a todos los personajes más importantes y medulares de la Europa de finales del siglo XIX; posee enormes cantidades de tierra; ha leído a Spencer y Henry George y sus teorías que niegan la propiedad privada y afirman una sociedad más desarrollada a partir de cierta socialización que supone un grado de madurez y cultura desde la naturaleza humana misma. A Nejliudov parece no faltarle nada, todo parece conseguirlo con enorme facilidad, mucho de eso le llega hecho y sin mayor esfuerzo; hastiado de ser príncipe, se hace militar y con ello pasa de ser un caballero aristócrata a experimentar que las cosas que desee las puede arrebatar por la fuerza y aún así acaban siendo suyas.

Maslova -o Katiusha, como también se le llama- ha trabajado en la mansión de las tías de Nejliudov; estas cuidan del príncipe, pues él es también huérfano desde muy niño. Entre Maslova y Nejliudov había afectos similares a los dables entre hermanos; las tías prevenían que la conjunta crianza de ambos 
no interfiriera con el crecimiento socialmente admitido para la aristocracia propia de Nejliudov. Un romance o un potencial matrimonio con Maslova sería no sólo contraproducente, sino indecente. Sin embargo, previo a marcharse Nejliudov para hacer carrera militar, el romance aparece entre ellos; los campos, los árboles y la naturaleza entera pueden testimoniar que aquella pareja se ha tomado de la mano, sienten con un mismo corazón y sus labios se han besado algunas veces. Lo que predomina es el corazón, un afecto casi mutuo entre uno y otro. Almas gemelas. Hasta ese momento, hay eso y nada más. Deseo de dialogar y compartir el mundo y la vida; deseo de charlar y tomar el té en los salones y las terrazas, de leer un mismo libro y escaparse y ocultarse entre el jardín para regalarse un sencillo e inocente beso.

De regreso, tres años después, Nejliudov es otro. Partió una alma gemela y complementaria a Maslova y retornó un hombre lleno de malos propósitos, un desenfrenado, un hombre animal, capaz de sacrificar a su placer a la humanidad entera. El hombre honesto había sido sustituido por esa otra naturaleza, la bestia humana.

En menos de tres días la bestia hizo de las suyas, justo después de las misas de Resurrección de la Semana Santa. Nejliudov acosó reiteradamente a la muchacha, y acabó violándola. Si bien ella le abrió la puerta con gusto y cierta reserva, lo hizo esperando afecto y amor, y negándose después le solicitaba que no prosiguiera en su intento animal. El príncipe fue bestia, concluyó pronto, se fue enseguida del cuarto de Maslova y sin decir una palabra, huía; dejó la casa a la mañana inmediata y le tiró a Maslova cien rublos, la cantidad que se pagaba a las prostitutas. La relación quedó trunca. A los dos meses Maslova estaba embarazada y fue echada del hogar que tanto la había acogido. El cargo: mujer fácil y disoluta.

El fruto de aquella relación tormentosa fue un niño, el cual -dadas las condiciones socioeconómicas tan adversas- murió a las semanas de nacido. Maslova se colocó como sirvienta en repetidas ocasiones y en cada una de ellas encontró -desde el amo hasta los hijos de este- quienes aprovechándose de su autoridad terminaban por violentarla sexualmente. Por último y convencida de que, en efecto, era la causa primera de tales tratos, se colocó en una casa de prostitutas donde le pagaban por lo que, según ella, era.

Precisamente en este lugar, trata con un comerciante viajero que desea sexo y licor. Agotado el dinero que porta y deseando beber más y divertirse con otras muchachas, le 
solicita a Maslova que vaya al hotel y traiga dinero. Ella trae el dinero. Luego, pasan al hotel y los propietarios de este le sugieren a Maslova que ofrezca al comerciante un líquido a fin de hacerlo descansar y soportar la jaqueca del día por venir. El dinero desaparece y el hombre muere envenenado. Maslova, el propietario y la empleada del lugar son procesados por asesinato y robo.

Se acostumbraba, en los juicios de la época, nombrar un jurado compuesto de nobles, comerciantes y pueblerinos. Nejliudov es parte del jurado, instancia que sobrevalora estar al lado del príncipe y se interesa -más que en el caso- en poner sus ojos sobre el cuerpo de Katiusha y en divertirse haciendo bromas, tomando y fumando después de cada sesión del juicio. Nejliudov teme ser reconocido por Maslova, pero esta no lo reconoce, y el jurado en pleno, después de escuchar las acusaciones y las pruebas testimoniales, no acepta que Katiusha sea culpable con intención ya sea del robo, ya sea de la muerte, aunque sí coadyuvante para que estos se dieran. Sin embargo, cegados por los deseos de divertirse y acabar rápido con el juicio -que por lo demás les ha parecido ridículo y excesivamente tedioso- olvidan mencionar que es culpable, pero sin intención, de donde resulta que Maslova es sentenciada a cuatro años de trabajos forzados en Siberia.

De todos los miembros del jurado, solo Nejliudov se percata del error garrafal. Se lo hace saber a todos y todos lo aceptan, pero no hacen nada por corregirlo. El fallo está dado y lo único es que la sentenciada misma apele el veredicto. A partir de ese momento, el príncipe decide hacer suya la causa; se comunica con altas autoridades y con la propia Maslova. Sin embargo, lo hace más por considerar que Katiusha está en esa posición por haber abusado él de ella -y así haberla impulsado a la prostitución y a esos momentos presentes-, que por considerar que el error se encuentra en la negligente manera como los jurados deliberaron su fallo. La culpa corroe a Nejliudov y el paso desde la protesta hasta el conformismo, por estar viviendo las consecuencias de ser una mujer deseable para todos, carcome por dentro a Katiusha.

En un propósito de restitución (resurrección) final, el príncipe intenta de mil maneras convencer a aquella de que se case con él. Ella no acepta. Él se convierte en un defensor de las causas sociales de los más necesitados, los campesinos y los presos especialmente. No logrando explicarse nada, atormentado interiormente, hace casi por hacer; a veces siente la felicidad y, a ratos, el asco más insoportable 
y se refugia en el sueño. Katiusha parece encontrar motivos para vivir en medio de su condena -otro preso que se figura haberse enamorado de ella y al que no quiere, pues ama a quien era príncipe hacía tres años pero, a la vez, lo odia y le es indiferente; ese Nejliudov que, finalmente, le ha obtenido el levantamiento de su pena y la proclamación de su inocencia.

Nejliudov no entiende nada. Un pastor inglés -el cual visita presos- le explica el sentido de aquello que humanamente parece no tener sentido del todo. No le entiende. Lee algunas páginas del Evangelio y empieza a llorar y reconoce que los seres humanos viven como viven, porque son humanos. La obra finaliza.

\section{La conciencia como experiencia trágica}

Al inicio de la primera parte, menciona Tolstoi (1991) que los seres humanos en vano se hallan hacinados entre la naturaleza (las hierbas, las avecillas, los animales, los gorriones, los abedules y los cerezos, los tilos, las estaciones, el zumbido de los trenes y de las abejas, el sol y la luna, las moscas) y los pétreos muros; en vano "se esfuerzan en desfigurar la tierra" (Tolstoi, 1991: 1) donde viven; en vano, pues confunden las cosas y llaman sagrado e importante a cosas que no son ni sagradas ni importantes. ¿En vista de qué es esto importante? En vista de que denota desde el inicio que la tragedia del hombre llega a descubrirse en su punto culminante justo en el momento cuando reconoce que ha descuidado el instante, el momento. Nos explicamos a continuación.

En la naturaleza humana -no en la naturaleza que rodea al hombre, que fue la citada en el párrafo precedente-, en la naturaleza humana-decimos- hay dos hombres, dos seres humanos: "En Nejliudov, como en todos los seres humanos, había dos hombres. Uno es espiritual, que buscaba el bien de todos, y otro, animal, que sólo perseguía el bien para sí mismo y por el que estaba dispuesto a sacrificar el mundo entero" (Tolstoi, 1991: 43).

Ahora bien, estos dos hombres resultan antagónicos y de alguna forma uno de ellos puede predominar sobre el otro: "el hombre animal se había apoderado de él, ahogando al espiritual" (Tolstoi, 1991: 43). Sin embargo, este ahogamiento no sucede de una manera inadvertida, soterrada, inconsciente. El ahogamiento, como tal, es el resultado de una lucha; la lucha sí es inconsciente: "Durante los dos días que faltaban para Pascua, se libró en su fuero interno una lucha inconsciente" (Tolstoi, 1991: 43). El fuero es el que es capaz de deliberar, el fuero es el tribunal de la 
conciencia y está en cada ser humano. El ser humano puede deliberar. Esta es la premisa de la cual, según Tolstoi, ha de partir la postulación de la doble naturaleza humana.

En efecto, el ser humano puede interrogar su conciencia y, es más, puede interrogar la conciencia de otros. El ser humano, de esta manera, está examinando las conciencias, está procurando conocer las intenciones, esto es, la verdad que hay en la acción de los otros. Dicho de otra manera, el ser humano -por medio del examen de la concienciapuede conocer las inclinaciones animales y espirituales de los otros y de sí mismo. Así, puede preguntar a otros: "—¿Cómo le dio usted los polvos? - Los eché en una copa de coñac. — ¿Por qué lo hizo? —No me quería dejar marchar. Me había cansado de estar con él" (Tolstoi, 1991: 35); “-¿Por qué ha sufrido? ¿Para qué ha vivido? ¿Lo sabe ahora?" (p. 293); "-Pero, ¿por qué los han matado? ¿Quién ha sido?" (p. 233).

Respecto a las interrogantes al propio fuero, estas se ofrecen en lo muy íntimo y en general encierran los motivos de la acción humana. Lindante con estas preguntas interiores está el estado de zozobra hacia lo nuevo por conocer ("- ¿Qué será de mí? ¿Qué va a ser esto?" [Tolstoi, 1991: 24]), se encuentra el tormento de quien no sabe si actúa o no (si viola o no; si se casa o no; si ama o no; si es prostituta o agredida; si cree en Cristo o acepta que todo sigue dando igual).

Las preguntas que se lanza la conciencia, generalmente, hacen evocaciones al pasado y, por lo común, también la conciencia trata de crear soluciones a ese pasado. De esta manera, la conciencia arrastra no sólo el peso de decidir, sino el de sentirse culpable y el de intentar reparar los males causados por su acción.

La recriminación de la conciencia es una de las principales características del príncipe Nejliudov, y su recriminación acaba muchas veces en tristeza, vergüenza y asco:

"'Esto es vergonzoso y repulsivo, repulsivo y vergonzoso', pensaba Nejliudov mientras regresaba a su casa por las calles que le eran tan conocidas (...) al entrar a aquella habitación [el cuarto de su difunta madre] recordó las relaciones que habia tenido con ella y le parecieron exentas de naturalidad. Esto también era vergonzoso y repulsivo. Se acordó que en los últimos momentos de la enfermedad de su madre le había deseado la muerte. Se decía que era para que se librara del sufrimiento, pero en realidad había sido para no verla sufrir." (Tolstoi, 1991: 73).

En efecto, la vergüenza es un indicador de la conciencia moral, es la turbación del ánimo causada por el miedo a la deshonra, al ridículo. 
La vergüenza convierte a su víctima en oprobio viviente, y el oprobio solo puede tener una sentencia y una exposición pública. El reo es el que, por antonomasia, debe sentir vergüenza. De una forma $u$ otra, el príncipe Nejliudov se confiesa reo. Un reo con libertad. Por su parte, el asco es una repugnancia que es causa de vómito, es la impresión desagradable, es el sujeto mismo quien es desagradable y causa del desagrado, es él mismo, en todo su ser. Experimentar asco de sí mismo y vergüenza de sí mismo es confesar que se carece de motivos para existir, es reconocer que no se vale nada. Por esta misma razón, la conciencia descubre el vacío humano, la finitud humana. Este descubrimiento es un terremoto. En el lenguaje de Tolstoi, es el descubrimiento de la crisis, de la crisis de la nebulosa de la conciencia moral.

La nebulosa es tal por ser aglomeración de innumerables estrellas indistintas, las que se agrupan formando una especie como de nube celeste; nebuloso es todo lo que está obscurecido por las nubes; es también lo tétrico, lo difícil de entender, lo que carece de lucidez y claridad. Decimos que la conciencia moral de los personajes de Tolstoi (1991), en Resurrección, aparecen con una conciencia nebulosa, y lo decimos porque efectivamente después de cada acción, tarde o temprano, el sujeto realiza elucubraciones que sólo pueden ser pospuestas por el sueño, por los cigarrillos o por el alcohol o un aparente pretendiente; $y$, en definitiva, totalmente desaparecidas con la extinción última del personaje (la muerte). Sólo la muerte apaga la conciencia, porque estar vivo es ineludiblemente caer en continuas elecciones y las elecciones siempre nos lanzan preguntas, antes y después de ellas.

En la obra que estudiamos, Resurrección, los personajes deambulan dentro de su conciencia. No cesan de moverse en ella y es que el movimiento de la conciencia es el signo de la vida. Quizá quien mejor ofrece esas características sea indiscutiblemente Nejliudov, el personaje principal. Es más, en él se ve con toda claridad que la conciencia le revela al hombre el paso de un acontecimiento hacia otros múltiples ya efectuados, o a otros por efectuar o incluso a acontecimientos ajenos, los de los demás:

"Y Nejliudov revivió el momento en que había alcanzado a Katiusha en el pasillo, le deslizó los cien rublos y se alejó presuroso. 'iOh ese dinero! ¡Oh qué vileza! - pronunció con la misma mezcla de horror y repulsión que sintiera entonces-. Solo un miserable puede proceder así. $Y$ yo soy ese miserable -exclamó en voz alta-. Pero ¿es posible que realmente lo sea? -se preguntó deteniéndose-. ¿Y qué soy si no? Además, ¿acaso eso es todo? ¿Acaso no 
es una ignominia mi relación con María Vasilievna y con su marido? [María era su amante, el marido era su mejor amigo $]^{\prime} Y$ mi actitud respecto de la herencia? Bajo el pretexto de que el dinero era de mi madre, disfruto de él, aunque considero ilegal la propiedad privada. Llevo una vida ociosa y observo una conducta reprensible. Mi proceder con Katiusha ha sido la coronación de todo lo demás. Soy un miserable, un canalla. Poco importa el juicio de los hombres, puedo engañarlos, pero no me engañaré a mí mismo." (Tolstoi, 1991: 74-75) [El destacado es nuestro e insiste en el carácter de resurrección]

En efecto, la conciencia desencadena los recuerdos, las tribulaciones más diversas; una experiencia atrae el mar de todas las experiencias. Y la conciencia humana se descubre culpable porque se adivina responsable, se atormenta porque es ineludible que se juzgue, porque la conciencia naturalmente juzga. La conciencia descubre el asco y la repulsión y la miseria del sujeto porque sabe de sus posibilidades y entiende que lo que fue, es y será, bien pudo ser de otra manera, bien puede ser de otro modo, bien podría ser de cualquier otra forma. La conciencia se examina y tiene la cualidad de descubrir que, en definitiva, la libertad que se tiene de actuar es un enorme problema, porque bien puede dominar el hombre espiritual como el hombre animal y ambos están en el hombre. La conciencia, por eso, nos descubre que el ser humano es finito y que si es honesto ha de sentir asco y repulsión por muchas cosas; pero, que si es más honesto ese asco y repulsión los ha de sentir ante todo por sí mismo. Por otra parte, el ser humano-que se reconoce repulsivo a sí mismo- concluye que un acontecimiento determinado puede ser la coronación de muchas de sus acciones y deliberaciones previas. Por lo tanto, ninguna acción llega ni se produce aislada y sobre el vacío $\mathrm{y}$, por eso, se debe asumir el peso de la total responsabilidad de las acciones efectuadas. Pero también descubre otras dos realidades tolstoianas: una, que el ser humano necesita una "depuración del alma"; la conciencia destaca que este es frágil y bestial, pudiendo dominar su otra naturaleza, la espiritual. Luego, es posible la depuración: ese estado anímico que sigue al estancamiento de la vida interior y en el cual esta se limpia de la basura acumulada en el alma (Tolstoi, 1991: 75). A estas crisis y depuraciones se sumaría, posteriormente, el recurso de seguir reglas (máximas), escribir en el diario e iniciar una vida nueva.

Pero, en segundo lugar, la conciencia se autopercibe como un instrumento para descubrir e iniciar cierta resurrección del ser humano. ¿Por qué? ¿Por qué parece que 
Nejliudov tiene una posibilidad a partir de la experiencia trágica que le reporta tener y emplear la conciencia? Porque "...el ser moral y libre, que es el único verdadero, el único poderoso y eterno, revelóse en Nejliudov. Y no pudo por menos de creerle. Por enorme que fuera la distancia entre lo que hubiera querido ser y lo que era, el sentimiento que se había revelado en él afirmaba que todo era posible" (Tolstoi, 1991: 75).

Sinteticemos lo que aquí sucede: 1) la conciencia descubre al personaje como moral y como libre, y ante la capacidad de ser dueño de sí y de su circunstancia; 2) la verdad, el poder y la eternidad se hallan en esta conciencia; 3) la fuerza de esta conciencia es tal que imprime convicción propia; 4) la conciencia navega entre lo que lo que fue, es y lo que debería ser; 5) la conciencia aparece, se revela, tiene entrada en la vida humana y se afirma en las posibilidades y como fuente de posibilidad.

Ahora bien, la conciencia -recordemos- se ha llenado de la experiencia que le ha producido asco y repulsión. Y tengamos entendido que estas nuevas posibilidades han nacido después de la depuración, de la resurrección, de dar lugar al hombre espiritual a partir del conocimiento y dominio del hombre bestia.
Por eso, no es de extrañar que, en su impotencia, en su aturdimiento y postración moral, la conciencia pida ayuda a Dios y le solicite perdón a este, como suelen hacer los niños:

"-Señor ayúdame, instrúyeme, ven a mi para purificarme de toda bajeza-. Al rogar a Dios que le ayudase, que penetrase en él para purificarlo, no se daba cuenta de que su plegaria estaba ya cumplida, El Dios que vivía en él se despertó en su conciencia. Y por eso experimentó una sensación de libertad, energía y placer de vivir, comprendiendo además la fuerza que representa el bien." (Tolstoi, 1991: 76).

Así resucita el ser espiritual que había dormido durante tantos años, así aparecen la ternura hacia sí mismo y hacia la grandeza de su alma.

\section{La rutina, ese sepulturero}

Mencionábamos cómo Tolstoi (1991) iniciaba la parte primera de Resurrección: haciendo alusión a que los hombres desconocían la naturaleza en la que se encontraban inmersos. Este tema viene a colación al tratar a la rutina. Cuando la costumbre deja de ser hábito y entonces ya no es racional ni virtuosa, se llega a actuar por actuar. La rutina es, en estricto sentido, la costumbre inveterada o irreflexiva. 
Entonces en el ser humano aparecen dislocadas sus naturalezas: la espiritual no responde, de hecho permanece casi ignorada, adormecida; la bestial actúa sin mayores consideraciones y se permite todas las posibles exageraciones o desproporciones. También, en este caso, los personajes y las acciones en Resurrección son fuente de ilustración.

En efecto, inicialmente encontramos a un príncipe Nejliudov caballeroso, casi pedante de tan aseado y correcto, que ha crecido con Katiusha; a esta la vemos jovial, pensativa y muy aristocrática, pese a su extracto franco de niña pobre y huérfana. Por costumbre, eran casi hermanos; por costumbre, sus conciencias crecieron sin manifestarse amor y suponiéndoselo recíprocamente. $\mathrm{Y}$ es el afecto espiritual el que rompe la costumbre una vez que juegan en el jardín y se llenan de pinchazos los dedos. Así surge el amor entre ambos.

Harto de hacer lo mismo y suponiendo el amor de Katiusha, marcha Nejliudov a hacerse militar. Por rutina militar, se hace afín a tratar con prostitutas y romper el corazón de las mujeres. Vuelve transformado en un hombre que es dominado por el animal, eso quiere ser y eso es. Viola a Katiusha, el afecto espiritual de esta hacia él es mancillado; en ella nace el propósito del olvido, mas no puede: tiene un hijo y ama a Nejliudov. Pero él se marcha. Al tiempo escribe para decir que hará visita. Kaitusha lo esperaba en la estación del ferrocarril, él no baja ni hace la visita. Katiusha llora el desamor, la indiferencia; se siente vejada y despreciada; al cabo de unos meses, su conciencia le da a entender que ella es responsable -en parte- de todo; es pobre, miserable y deseable, tiene todo para prostituta. Se acostumbró al trajín: entre ser violada por todos los señores y ser prostituta, está el dinero como diferencia. Se acostumbró tanto que, en su rutina, perdió a Dios. Se acostumbró tanto a la rutina de olvidar a Nejliudov que, en el juicio, no lo reconoce; entró tanto en la rutina del olvido del amor que, intuyendo el amor, le resulta repulsivo y prefiere la rutina de dejarse amar por un preso a quien no sabe si ama ni si la ama.

Incluso los miembros de la Corte de Justicia están enfrascados en la rutina: el fiscal es estúpido y todos lo saben, por eso lo ignoran al hablar; se sabe quién llega tarde y a qué hora el juez debe verse con su amante; los abogados, hartos de casos de gente que no paga, se cansaron de argumentar defensas; las pruebas en un juicio se miran como objetos cualquiera y, por rutina, va a la cárcel quien generalmente es inocente; por rutina, también, se acepta que a los presos se los castigue y se los meta en mazmorras 
antihumanas junto al balde de sus excrementos; por rutina, los soldados fuman cigarrillos y las presas, clandestinamente, se emborrachan; por rutina, la propiedad pertenece a los amos, aunque no sepan cultivarla y no la necesiten para vivir; por rutina, un militar tiene religión $y$ procede a fusilar a presos que sabe son inocentes; por rutina, un muerto es un muerto sin importar su nombre; por rutina, se vive como muerto y no se cree que existan posibilidades para cambiar.

Este es el panorama de la rutina en Resurrección. Ahora bien, ¿qué significa? Significa que el ser humano corre el riesgo de anestesiar la conciencia humana, la voz interior propia y que en ese aturdimiento moral, en esa falta de reflexión que es la rutina, la conciencia ya no actúa como tal y permanece el hombre bestial y oportunista. Significa que este se acostumbra a las condiciones más desgraciadas y contradictorias, y a todas las juzga "normales". Así, el príncipe Nejliudov viola a Katiusha porque un militar hace el sexo con la mujer que desee y, a continuación, le arroja los cien rublos. Significa que los pobres se aceptan pobres y la mujer violada como la causa de sus desgracias psicoafectivas; significa que los campesinos prefieren pagar por el suelo que es de su amo - a la tercera parte de lo que producen en un año- a que su amo les regale las tierras que ellos y sus hijos necesiten para vivir. Significa que la política y la vida social son sinónimos de falta de principios morales y espirituales y que así todos los asumen. En consecuencia, la sociedad es un grupo de humanos donde todos se ven como "los todos": todos comen, todos sufren; todos duermen, entre vómitos y excrementos; todos presos, todos sentenciados, todos parias, todos a Siberia. Todos son miserables, sí, aunque se sea príncipe, general, gobernante, la iglesia con sus privilegios o los magnates con sus industrias y campos. Todos anestesiados de su situación.

¿La causa de todo ello? No percatarse, no tener ejercicio de la conciencia. Estar en el tiempo y ser del tiempo, estar enajenado de la vida propia, porque la vida tiene ese problema: perdido el dominio del espíritu sobre la bestia, la bestia se envilece y crea y acepta la rutina. Nadie se percata de nada en la rutina, porque nadie se percata de su ser espiritual.

La solución sería creer en Dios; pero, cuando se ha sufrido la injusticia social ya no queda sino conformarse con eso, y la rutina nos lo hace tan propio; entonces, creer en Dios está de más: “- -No me salga ahora con esas! Todos son iguales. ¡Dios! ¿De qué Dios me habla? Debió pensar en él entonces [cuando usted me estaba violando]" 
(Tolstoi, 1991: 116). En efecto, para quien está en el lastre de la rutina, creer en Dios es casi un milagro, "no se puede creer en eso-, sino que sería preciso tener fe en esa creencia" (Tolstoi, 1991: 99). Esto último es también trágico: si la conciencia se salva con Dios, la conciencia se resiste a Dios. Y es más trágico aún: quien hoy es hombre espiritual, ayer pudo haber sido hombre bestial, dejando en la postración humana del envilecimiento, del no perdón y del resentimiento a quien - por todo lo vivido- ya no quiere ser hombre espiritual; alguien que si llora no es por dolor, sino por saberse humillado y ofendido. El resultado, entonces, es que el ser humano tiene la capacidad intrínseca de convertirse a sí y a los demás en una alma doliente (Tolstoi, 1991: 271), en un ser sin sentido (p. 288), en un ser cansado de la vida (p. 288). Y finalmente, la tragedia humana se trasciende en un ser superior, debido a la impotencia humana: de nada sirve el sacrificio de nadie por arreglar el sufrimiento de otro, por tranquilizar a las almas dolientes, tal resurrección no es posible, pues ningún ser humano debe morir por otro, pues todo ser humano debe vivir y encargarse de sí mismo y dejar a los demás ${ }^{1}$. De ese destino con lo divino trataremos a continuación.

\section{Aprovechar el instante: breve semblanza de Tolstoi a Kierkegaard}

¿Culpable o no culpable? ¿O esto o lo otro? ¿O una vida ética o una vida religiosa? ¿O creyente o pagano? Entre estas dimensiones situaría Kierkegaard (1968) la libertad, la angustia y aprovechamiento del tiempo presente.

El sujeto kierkegaardiano es frágil, se encuentra entre la subjetividad y la certeza objetiva. Descubre que su existencia no es un silogismo ni puede ser silogizada ${ }^{2}$. Al contrario, la existencia se descubre como un mar de posibilidades. Aquí coinciden Tolstoi (1991) y el danés. Estas posibilidades son el potencial material de la elección, por eso de la acción. Elegir y actuar es lo que siempre se hace, es una cadena de repeticiones. Ahora bien, la susceptibilidad de la repetición

1. Un ser humano existente particular de seguro no es una idea, y su existencia es ciertamente muy distinta de la existencia conceptual de la Idea. Una existencia, como un ser humano particular, es sin duda una imperfección si se compara con la vida eterna de la Idea, pero es una perfección en comparación con no existir del todo (Kierkegaard, 1968: 293-294).

2. Así como el movimiento, la existencia es una ejercitación extremadamente difícil. Si la pienso, la elimino; y eliminándola no la puedo pensar. Podría parecer correcto afirmar que sí hay algo que se niega al pensamiento: la existencia. Pero la dificultad retorna. La existencia establece de nuevo la conexión, por el hecho de que el sujeto pensante existe (Kierkegaard, 1968: 280). 
estriba en la misma subjetividad, esta especula y es movida por una pasión que, por parcial que sea, es siempre una pasión hacia la verdad. En otras palabras, en cada elección el hombre se juega su existencia y en el caso del caballero de la fe, la existencia se juega en cada instante, porque en cada instante se juega la eternidad. Cada instante es un encuentro con Dios, una divinización en algún sentido, una ocasión para que se perfeccione el caballero. Por tanto, cuando la existencia se llena de pasión, la existencia se vive en lo impronunciable (no comunicable y, por eso, eminentemente personal y trascendental a la vez) del instante. Sin embargo, la existencia también se vive en el marco de la comunicación heterogénea, que no deja de ser un problema, pues crea las más diversas situaciones humanas. La comunicación heterogénea puede darse en cualquiera de los tres estadios kierkegaardianos, pero no por eso es sencilla. Las situaciones que produce el que el ser humano sea un hombre social son diversísimas: desde enamorar a una muchacha y luego no casarse con ella, hasta besar a la madre en el borde de la muerte, hasta proferir un discurso eminentemente cristiano contra el arzobispo y la iglesia oficial.

Esto quiere decir que la comunicación heterogénea, la que no tiene un carácter salvífico, interiorista -según Kierkegaard- es, en el fondo, un intento por hallar la libertad; es, de alguna forma, un intento por superar al absoluto y a toda necesidad estrictamente racionales; es, en fin, la búsqueda de la realidad más allá de la realidad pensada.

La realidad kierkegaardiana es el individuo libre y que construye su mundo, su horizonte de posibilidades; la realidad kierkegaardiana es que el individuo no es la teoría (Kierkegaard, 1967: 280), sino la inagotable vida y que esto es así, porque la existencia humana se encierra en posibilidades que garantizan su libertad y que estas se encuentran enmarcadas dentro del instante; siendo, además, que el instante es -para el caballero de fe-el medio y la oportunidad para alcanzar la unión de lo finito con lo infinito. Por este motivo, al existente religioso no le sirve perder el tiempo; lo mismo que al existente ético no le estimula pisotear las normas morales; o al esteta, faltar a la belleza.

La realidad humana de Kierkegaard es existencial, porque es la concatenación de elecciones, de rupturas y saltos; porque lo que da lugar al salto de una modalidad de vida a otra, de una elección a otra es, en definitiva, la voluntad del individuo que se atreve a creer en el salto. Una vez más, la verdad kierkegaardiana estriba en el sujeto, no en la substancia metafísica. Así, la 
única riqueza que puede hallar el ser humano a su alcance es su mismo yo, la relación de sí consigo mismo; descubierto esto, verá que su vida finita se compone de instantes que son pasos imprescindibles para el encuentro con el ser infinito y la vida infinita. En efecto, con esto Kierkegaard está planteando un nuevo concepto de la posibilidad y de la realidad; por eso, llegando a la impotencia de la subjetividad (de la estética a la ética, de la ética a la religión), se concluye por desesperar y hacer que la voluntad salte y se juegue toda la vida (finita e infinita) en la religiosidad.

De la misma forma que en Tolstoi (1991), la emoción humana se trasluce en la subjetividad, en este caso es la angustia que no deja descansar al sujeto; la subjetividad se tiñe de temblor y temblor ante Dios, pues cada acción es motivo de condena o salvación. Por eso, se angustia predominantemente el hombre espiritual, el caballero de la fe; el que no es espiritual vive del placer o de la normatividad; pero esta vida decepciona, desespera, de aquí pasará a la angustia. Sin embargo, una cosa es pasar a la angustia en cada elección, y otra distinta es vivir en la angustia (Kierkegaard, 1951: 145). De hecho, la angustia es inevitable y de hecho, también, no se puede creer sin angustiarse. El creyente se justifica por la fe, esto es, por creer en medio de la angustia y pese a la angustia.

El hombre de fe se guía por la adecuación de su fe, una fe que no es racional y que se apoya en premisas paradójicas: un estado de incertidumbre objetiva, la cual se relaciona con creer en una verdad trascendental, personal y existente, un Dios hombre que no se ve, y que se ha realizado como paradoja histórica gozando de la capacidad de unir el finito con el infinito (Cristo).

Al igual que en Tolstoi (1991), la enajenación sería la pérdida de la conciencia, el ofuscamiento del sujeto en un modo de vida que no es el religioso. La única salida viable es, por lo demás, la repetición de la acción, que no es sino la génesis de sí mismo, el reflejo de su acción, su autoconstrucción subjetiva, exclusivamente humana. De esta construcción se sabe consciente y la vida misma le ofrece la oportunidad de resucitar - por medio de la desesperación- de su estado de vida. Ahí es, precisamente, cuando puede salvarse; esto es, cuando saltando puede saltar hacia Dios. De esa forma, pasa del querer ser sí mismo a la identificación de su ser en el ser intemporal planeado por Dios (caballero de fe, hombre cristiano, criatura redimida). En otras palabras, si el ser humano se quiere salvar, debe admitir que debe aniquilarse a sí mismo; debe aceptar que el paso al cristianismo 
es el único territorio de salvación, que este paso es el exceso de posibilidades y que incluso la irrestricta exigencia de desesperar de no ser sí mismo; por ello, la vida mortal es ausencia de sí y encuentro religioso con Dios. Luego, la relación con Dios es una relación con el ser a partir de la voluntad. Si no se quiere estar muerto en vida por el pecado y la tentación de la razón (ética) y del placer (estética), se ha de aceptar que el único e irrenunciable tratamiento para la enfermedad mortal es la ruptura, desesperar de la vida ética y de la vida estética. Sin embargo, Kierkegaard es inmensamente radical y, con ello, aumenta el peso de la tragedia humana: "yo no elegí el camino que conduce hacia Dios, porque no he tenido elección" (Kierkegaard, 1951: 359). El camino de salvación no se elige, es el único que queda; lo que se elige es saltar. En consecuencia, la única ruta posible es la de ejercitarse en la milicia del cristianismo; milicia, sí, porque muchos son los llamados y pocos los escogidos. Milicia, pues exige la renuncia de sí y asumir la vida como camino al cielo, la vida como "un esse que non posse, un sujeto que no confía en sí mismo para venir a creer en quien no ve $\mathrm{y}$ al que uno tuviese que confiarse, atreviéndose a elegirle pese a parecer ser el único en quien no se pudiese creer, es decir, confiarse a él" (Kierkegaard, 1951: 224).
Al igual que en Tolstoi (1991), el instante no deja de ser decisivo, valioso, eterno. El tiempo es el fundamento para la acción, la materia casi prima. Sin embargo, es más claro en Kierkegaard que en Tolstoi cómo ese tiempo llega a tener un revestimiento salvífico. El hombre si quiere puede salvarse, si salta al estadio religioso (Kierkegaard); si los evangelios divinamente revelados tocan el corazón humano, por ejemplo, gracias a que un hombre espiritual se los ofrece al hombre bestial (Tolstoi, 1991). Trágica advertencia, sin embargo: la fuente del cambio ha sido revelada; no es que el hombre quiso salvarse y por eso se salva y halla a Dios. No, el hombre se salva, en ambos casos o autores, porque Dios previamente lo buscó y, por eso, se reveló en su Hijo o en los Evangelios. Es 1o que descubre Nejliudov al final de la obra: en los evangelios está la respuesta de todo; el consuelo y la alegría sólo se encuentran en los momentos en los cuales el hombre se humilla (Tolstoi, 1991), en los momentos en que el hombre desespera de sí y salta a Dios (Kierkegaard, 1951 y 1967) Dios estuvo ahí siempre y su verdad no cambió nunca, él buscó al hombre antes de que el hombre lo buscara. Llega un día cuando el hombre animal, el esteta y el ético lo reconocen.

Sí, lo reconocen. Por eso, tanto en Tolstoi (1991) como en 
Kierkegaard (1951 y 1967) la solución es similar, pues no hacen falta castigos ni sentencias de iglesias, ni gran memoria de textos: "Lo único sensato, pues, era que los hombres dejaran de hacer lo que no era inútil, sino también nocivo, cruel e inmoral" (Tolstoi, 1991: 295). Lo sensato, lo existencial verdaderamente, dirá Kierkegaard (1951), es asumir la existencia religiosa y desesperar de toda la vida estética y ética; es consagrarse como un discípulo militar de aquel que, siendo Dios, se convirtió en salvación y culpa por todos los hombres.

Negar este paso de conversión es, en Kierkegaard (1951), permanecer en el desamor y en el uso de la lógica; en el caso de Tolstoi (1991), es hacerse ciego a la realidad de que los criminales no mejoran con castigos, de que los fiscales, los jueces y los carceleros no son menos criminales por el hecho de su profesión que cualquiera de los que está preso. Lo que cambia al hombre es Dios, no es el hombre. Lo malo en el hombre está en el hombre, no le viene de fuera. El hombre es malo cuando no domina el estado de vida en el cual va a vivir, esto le produce desasosiego y, por eso, se refugia en lo estético (fuma, toma, seduce mujeres, se hace militar, causa injusticias sociales, entra en la rutina) o en lo ético (es un moralista -un juez, un jurado de vividores e ignorantes, un sacerdote condenador, unas tías que te crían y luego te echan a la calle por estimarte puta, un Dios que te prefiere pobre y enfermo a gozar de salud y terrenos comunales-) y así, perdido entre la rutina, se llega a sentir asco de sí, repugnancia, angustia, desesperación, llega a sentirse miserablemente culpable. La tragedia va en el hombre, en su naturaleza. Su salvación está en Dios; pero el juego trágico es tan sutil que es Dios quien conmueve al hombre, es él quien le busca; el hombre -por sí- no puede hacer nada. No puede hacer nada, su destino es tener dos naturalezas y contar con la libertad y su libertad -aunque él no quiera- se le ofrece siempre y lo construye siempre.

\section{Conclusiones}

1. La vida del ser humano es trágica sin Dios.

2. El ser humano es trágico en su naturaleza, su naturaleza es libertad y la libertad lleva a la angustia y a la desesperación; en Tolstoi (1991), la libertad es el elegir y hacer del hombre espiritual, y el elegir y el hacer del hombre bestial.

3. El elegir, en última instancia, causa el dolor propio y ajeno y obliga a reconocer la irremediable vileza humana, que se ha afianzado entre los descuidos de aquello que tuvimos 
tan cerca y transitorio: las oportunidades de existir a los instantes.

\section{Bibliografía}

\section{A. Fuentes tolstoianas}

Tolstoi, L. (1991). Resurrección. Obras escogidas. [Trad. Irene y Laura Andresco]. Madrid: Aguilar. (1-301)

Tolstoi, L. (1901). Diario. Madrid: Casa de la Cultura.

Tolstoi, L. (1891). ¿Qué es el arte? Madrid: España Moderna.

\section{B. Fuentes kierkegaardianas}

Kierkegaard, S. (1951). ¿Culpable? ¿No culpable? Etapas en el camino de la vida. [Trad. Juana Castro]. Buenos Aires: Santiago Rueda.

Kierkegaard, S. (1961). Diario. [Trad. Cornelio Fabro]. Roma: Brescia Editrice.

Kierkegaard, S. (1966). Either o Eithert. Trad. D.F. Swenson y W. Lowrie. New Jersey: Princeton University Press, 1966.

Kierkegaard, S. (1967). El concepto de la angustia. Madrid: Guadarrama.

Kierkegaard, S. (1968). Concluiding Unscientific Postcript. [Trad. D. F. Swenson y W. Lowrie]. New Jersey: Princeton University Press.

Kierkegaard, S. (2001). Migajas filosóficas. Madrid: Trotta.

\section{Bibliografía complementaria}

Bergson, H. (1948). Esaai sur les donées inmediates de la conscience. Paris: PUF.

De Waehlens, A. (1973). Existence et signification. Paris-Lovaina: Mauwelarts.

Embree, L. (2003). Análisis reflexivo. Una primera introducción a la investigación fenomenológica. IA First Introduction into Phenomenological Investigation. Jitánfora: Red Utopía, Jitánfora.

García Baró, M. (1993). La verdad y el tiempo. Salamanca: Sígueme.

García Baró, M. (1999). Vida y mundo. La práctica de la fenomenología. Madrid: Trotta.

Jaspers, K. (1969). Origen y meta de la historia. Madrid: Revista de Occidente.

Moreno Márquez, C. (1998). Tráfico de almas. Ensayo sobre el deseo de alteridad. Valencia: Pretextos.

Ortega y Gasset, J. (1983a). El hombre y la gente. Obras completas, vol. VII. Madrid: Revista de Occidente/Alianza Editorial.

Ortega y Gasset, J. (1983b). Sensación, construcción e intuición. Obras completas, vol. XII. Madrid: Revista de Occidente/Alianza Editorial.

Ortega y Gasset, J. (1983c). Sobre el concepto de sensación. Obras completas, vol. XII. Madrid: Revista de Occidente/ Alianza Editorial.

Rodríguez Húescar, A. (1974). Para una teoría de la posibilidad basada en el pensamiento de Ortega. Revista de Occidente, 140, 196-213. 
